УДК 519.6

${ }^{1}$ Олег Васильович Боровик (докт. техн. наук, професор)

${ }^{1}$ Людмила Володимирівна Боровик (канд. психол. наук, доцент)

${ }^{2}$ Микола Віталійович Красовський

${ }^{1}$ Національна академія Державної прикордонної служсби Украӥни імені Богдана Хмельницького, Хмельницький, Украйна

${ }^{2}$ Хмельницький національний університет, Хмельницький, Украйна

\title{
МЕТОД ПОШУКУ РАЦІОНАЛЬНОГО КОМПРОМІСУ В ОДНОМУ КЛАСІ ЗАДАЧ БАГАТОКРИТЕРІАЛЬНОЇ ОПТИМІЗАЦІЇ ПРИ РОЗКРИТТІ НЕВИЗНАЧЕНОСТІ ЦІЛЕЙ, ЩО ЗАДАЮТЬСЯ ФУНКЦІЯМИ ОДНІЄї ЗМІННОї
}

Для значного класу формалізованих задач системного аналізу важливою проблемою є розкриття невизначеностей. Формально задачі розкриття невизначеностей у системному аналізі та теорії дослідження операцій багато в чому схожі. Проте є й принщипові відмінності, щзо полягають у наступному. Задачі дослідження операџій мають більший ступінь формалізації, оскільки в них зазвичай апріорі задано всі обмеження, припущення, вихідні дані та математичні моделі. У задачах системного аналізу частину обмежень, припущень $і$ вихіднх даних наперед не вивчено, інформацію про них уточнюють у прочесі формалізачії та розв'язання задачі. На сьогодні залишається актуальним завдання розкриття невизначеності иілей у багатокритеріальних задачах прийняття рішень, які зводяться до задач системного аналізу “м'якої формалізації”. Однією з таких є задача пошуку раціонального компромісу при багатокритеріальній оптимізації для сукупності функцій однієї змінної.

У роботі: визначено клас задач розкриття невизначеності иілей, щзо визначаються функціями однієї змінної; здійснено аналіз існуючих підходів і методів розкриття невизначеності иүілей, а також чітко окреслено коло проблемних питань, щзо мають місце при їх застосуванні; запропоновано авторський метод розв'язування визначеного класу задач у визначених межах застосування; здійснено його алгоритмізацію і програмування, а також оцінено застосування на різних прикладах.

Ключові слова: системний аналіз; багатокритеріальна оптимізація; невизначеність иілей; область Парето; формалізачія; раціональний компроміс.

\section{Вступ}

Для значного класу формалізовних задач системного аналізу важливою проблемою $\epsilon$ розкриття невизначеностей. Це зумовлено різноманітністю цілей, властивостей i особливостей об'єктів системного аналізу. Прикладні задачі, які не містять невизначеностей, $\epsilon$ скоріше винятком, ніж правилом. Адекватний опис проблеми зазвичай містить різного типу невизначеності, що відображає той природний стан, у якому перебуває дослідник. Будь-яке його знання завжди є відносно неповним і неточним. Це безпосередньо випливає 3 теореми Геделя про неповноту [1] та еволюцію розвитку людського пізнання.

Формально задачі розкриття невизначеностей у системному аналізі та теорії дослідження операцій багато в чому схожі. Проте $є$ й принципові відмінності у підходах до формалізації, розв'язання i реалізації на практиці. Вони полягають насамперед у тому, що задачі в теорії дослідження операцій мають більший ступінь формалізації, оскільки в них зазвичай апріорі задано всі обмеження, припущення, вихідні дані та математичні моделі. У задачах же системного аналізу частину обмежень, припущень і вихідних даних наперед не вивчено. Інформацію про них уточнюють у процесі формалізації та розв'язання задачі.

Найпоширенішими на практиці $\epsilon$ невизначеності цілей, ситуацій, конфліктів. Суть цих невизначеностей наведена у роботі [2]. На сьогодні залишається актуальним завдання розкриття невизначеності цілей у багатокритеріальних задачах прийняття рішень.

Постановка проблеми. У загальному випадку під час дослідження об'єкта в цілому виникає потреба в узгодженні його цілей. При цьому для одних цілей оптимальні розв'язки відповідають мінімальному значенню відповідного критерію, а для інших - максимальному. Деякою заміною змінних ці задачі нескладно звести до єдиного типу критеріїв і одного типу задач оптимізації. Їх можна розглядати як задачу багатокритеріальної оптимізації [3]:

$$
\mathrm{f}_{1}(\overline{\mathrm{x}}) \rightarrow \max _{\overline{\mathrm{x}} \in \mathrm{D}}, \mathrm{f}_{2}(\overline{\mathrm{x}}) \rightarrow \max _{\overline{\mathrm{x}} \in \mathrm{D}}, \ldots, \mathrm{f}_{\mathrm{m}}(\overline{\mathrm{x}}) \rightarrow \max _{\overline{\mathrm{x}} \in \mathrm{D}}
$$

Найкращим розв'язком задачі (1) буде таке значення $\overline{\mathrm{x}}$, за якого умови виконуються одночасно для всіх цільових функцій. Однак на практиці це нездійсненно, оскільки функції $\mathrm{f}_{\mathrm{k}}(\overline{\mathrm{x}}), \mathrm{k}=1,2, \ldots, \mathrm{m}$ різні за природою (у загальному випадку їх визначають критерії різної природи - фізичного, технічного, економічного чи іншого змісту). Тому екстремуму кожна функція

(C) О.В. Боровик, Л.В. Боровик, М.В. Красовський

Modern Information Technologies in the Sphere of Security and Defence № 1(31)/2018 ISSN 2311-7249(Print)/ISSN2410-7336(Online) 
досягає для свого значення $\overline{\mathrm{x}}, \mathrm{i}$ майже неможливо знайти таке значення $\overline{\mathrm{x}}^{0}$, за якого забезпечуватиметься раціональний компроміс заданих цілей. Для знаходження раціонального компромісу застосовують два основні підходи. Суть першого підходу - виключити 3 аналізу заздалегідь неприйнятні варіанти розв'язків. Суть другого - використати прийоми й методи зведення багатоцільової задачі до типової задачі оптимізації 3 одним критерієм та розв'язати ії. Однак навіть у випадку, коли функції $\mathrm{f}_{\mathrm{k}}(\overline{\mathrm{x}}), \mathrm{k}=1,2, \ldots, \mathrm{m} \quad \epsilon$ функціями однієї змінної, часто виникають ситуації, коли пошук раціонального компромісу $\epsilon$ непростою задачею.

Аналіз останніх досліджень і публікацій. Прийняття рішень у задачах багатокритеріальної оптимізації може реалізовуватись по-різному: на основі урахування досвіду, інтуїції, здорового глузду, математичних розрахунків. В останньому випадку застосовуються різні підходи. Наприклад, коли цільові функції і обмеження складно формалізуються, застосовується метод аналізу ієрархій [4]. Якщо ж задача може бути “жорстко" формалізована, для іï вирішення застосовуються методи дослідження операцій [5-6]. Інші випадки досліджуються методами системного аналізу [2] із застосуванням самих різноманітних підходів i методів, наприклад тих, що описані у працях [7-8].

Незважаючи на увагу, що приділена науковцями останньому класу задач, на сьогодні залишаються не до кінця вирішеними питання вибору методів для розв’язування цих задач $i$ оцінки об'єктивності результатів, що отримуються при їх застосуванні.

Мета статті. Саме тому метою даної роботи $\epsilon$ дослідження можливості застосування різних методів при розкритті невизначеності цілей, що задаються функціями однієї змінної, і обгрунтування методу, який би забезпечував об'єктивність результату.

\section{Виклад основного матеріалу дослідження}

Для досягнення мети вбачається за доцільне:

чітко окреслити клас задач розкриття невизначеності цілей, що досліджуватиметься у роботі;

здійснити аналіз існуючих підходів і методів розкриття невизначеності цілей, а також чітко окреслити коло проблемних питань, що мають місце при їх застосуванні;

проаналізувати можливий підхід щодо їх вирішення та оцінити його ефективність.

Отже, розглянемо задачу розкриття невизначеності цілей, що визначаються функціями однієї змінної, у наступній постановці.

Знайти таку точку $\mathrm{x}$, у якій

$$
\begin{aligned}
& \mathrm{f}_{1}(\mathrm{x}) \rightarrow \max _{\mathrm{x} \in \mathrm{D}}, \mathrm{f}_{2}(\mathrm{x}) \rightarrow \max _{\mathrm{x} \in \mathrm{D}}, \ldots, \mathrm{f}_{\mathrm{m}}(\mathrm{x}) \rightarrow \max _{\mathrm{x} \in \mathrm{D}} \\
& \text { за умов }
\end{aligned}
$$$$
f_{1}(x) \geq f_{1}^{*}, f_{2}(x) \geq f_{2}^{*}, \ldots, f_{m}(x) \geq f_{m}^{*} .
$$

У (2) D - це область (проміжок, інтервал), що знаходиться у множині дійсних чисел $\mathrm{R}$.

$$
\mathrm{y}(3) \mathrm{f}_{1}^{*}, \mathrm{f}_{2}^{*}, \ldots, \mathrm{f}_{\mathrm{m}}^{*} \in \mathrm{R}
$$

Аналіз існуючих підходів $i$ методів розв'язування задачі (2)-(3) та проблемні питання, щуо мають місие при їх застосуванні.
Існуючий підхід до розв'язування задачі (2)-(3) полягає в реалізації двох етапів: виключення 3 аналізу заздалегідь неприйнятних варіантів розв'язків; розв'язування багатоцільової задачі в області прийнятних варіантів розв'язків.

Реалізація першого етапу пов'язується 3 пошуком області прийнятних варіантів розв'язків (області Парето) [2].

Виділення області Парето для часткового випадку досліджуваної задачі можна оцінити 3 рис. 1.

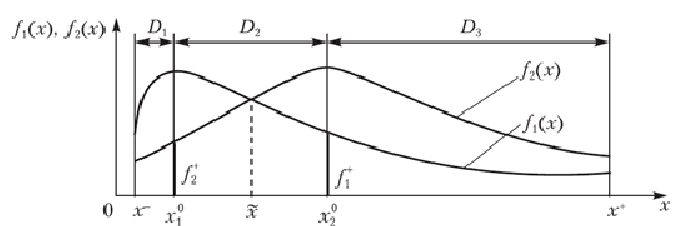

Рис. 1. Виділення області (множини) Парето у частковому випадку, коли цільові функції с функціями однісї змінної

3 рис. 1 видно, що областю Парето для аналізованого випадку є область $\mathrm{D}_{2}$.

У загальному випадку вид області Парето можна оцінити 3 рис. 2.

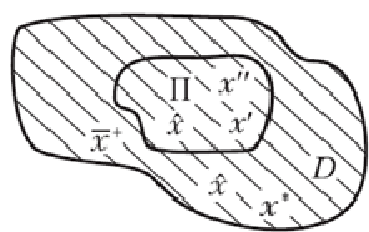

$D-$ вихідна множина

П - множина Парето

Рис. 2. Ілюстрація підходу до знаходження множини Парето у загальному випадку

У теорії прийняття рішень принцип Парето стверджує, що раціональний розв'язок багатокритеріальної задачі або раціональний компроміс у багатоцільовій задачі лежить серед х що належать множині Парето. Однак принцип Парето не дає змогу виділити єдиний розв'язок. Він дозволяє лише звузити множину можливих альтернативних розв'язків. $\mathrm{y}$ розглянутому прикладі (рис. 1) раціональний розв'язок потрібно шукати в області $\mathrm{D}_{2}$.

При пошуку області Парето задачі (2)-(3) проблемними моментами є наступне. По-перше, області Парето може не існувати. По-друге, область Парето може являти собою не один проміжок чи інтервал, а їх сукупність.

Загальний випадок при цьому такий: область Парето існує і являє собою один проміжок чи інтервал. Саме цей випадок аналізуватиметься у подальшому.

Слід зазначити, що питання про те, який розв'язок (або яке значення $\mathrm{x} \in \mathrm{D}_{2}$ у прикладі рис. 1) раціональний, - залишається відкритим. Справді, задача знаходження раціонального компромісу має неформальний характер через вплив кількох факторів. По-перше, важливість різних цільових функцій може залежати від низки об'єктивних факторів. По-друге, важливість цільових функцій може залежати також від суб'єктивних факторів. По-третє, вибір пріоритету 
цілей можуть визначати додаткові умови або обмеження.

В усіх розглянутих випадках побудова множини Парето дозволяє одержати додаткову інформацію, що дає якісну оцінку під час зіставлення різних варіантів. Особа, яка приймає рішення (ОПР), на підставі аналізу множини Парето може оцінити, як збільшення однієї цільової функції позначається на інших.

Із наведеного прикладу (рис. 1) випливає, що в точці $\mathrm{x}_{1}^{0}$ має максимум $\mathrm{f}_{1}(\mathrm{x})$, але мінімум $\mathrm{f}_{2}(\mathrm{x})$, у точці $\mathrm{x}_{2}^{0}$ досягає максимуму $\mathrm{f}_{2}(\mathrm{x})$ i мінімуму $\mathrm{f}_{1}(\mathrm{x})$, у точці $\widetilde{\mathrm{x}}$ справедлива рівність $\mathrm{f}_{1}(\widetilde{\mathrm{x}})=\mathrm{f}_{2}(\widetilde{\mathrm{x}})$. Який із цих варіантів кращий, визначає ОПР. Якщо ОПР вважає, що критерії рівнозначні, то раціональним буде варіант $\widetilde{\mathrm{x}}$, коли $\mathrm{f}_{1}(\widetilde{\mathrm{x}})=\mathrm{f}_{2}(\widetilde{\mathrm{x}})$. Якщо важливіша $\mathrm{f}_{1}(\mathrm{x})$, то, мабуть, раціональний розв'язок лежить в інтервалі $\left[\mathrm{x}_{1}^{0} ; \widetilde{\mathrm{x}}\right)$. Якщо важливіша $\mathrm{f}_{2}(\mathrm{x})$, то раціональний розв'язок лежить в інтервалі $\left(\widetilde{\mathrm{x}} ; \mathrm{x}_{2}^{0}\right]$. У двох останніх випадках певна міра переваги однієї функції над іншою залишається суб'єктивною мірою ОПР.

Однак часто трапляються випадки, в яких відсутня можливість суб'єктивного впливу на визначення переваги однієї функції над іншою в області $\mathrm{D}_{2}$, або в іiі частинах, наприклад в областях $\left[\mathrm{x}_{1}^{0} ; \widetilde{\mathrm{x}}\right)$ чи $\left(\widetilde{\mathrm{x}} ; \mathrm{x}_{2}^{0}\right]$. Саме цей випадок $\epsilon$ проблемним при пошуку раціонального компромісу задачі (2)-(3) i саме йому буде приділена увага в подальшому.

Кількісно міру переваги цілей прийнято характеризувати коефіцієнтом важливості кожної 3 них. Введення таких коефіцієнтів дає змогу реалізувати другий етап розв'язування багатоцільової задачі в області прийнятних варіантів розв'язків.

Реалізацію другого етапу, як правило, пов'язують iз застосуванням одного 3 методів лінійної згортки, технічних обмежень, послідовного розкриття невизначеності цілей, зведенням вихідної задачі до системи рівнянь. Кожен із цих методів може застосовуватись за окремих умов і забезпечувати отримання результату. Застосування вказаних методів пов'язується 3 реалізацією певної ідеї фізичного змісту.

Розглянемо особливості застосування цих методів у загальному випадку i визначимо проблемні моменти у випадку застосування до досліджуваної задачі.

Метод лінійної згортки.

Суть методу полягає в тому, що замість $\mathrm{m}$ заданих цілей, описуваних функціями $\mathrm{f}_{\mathrm{i}}(\mathrm{x}), \mathrm{i}=\overline{1, \mathrm{~m}}$, вводять одну узагальнену ціль, описувану функцією вигляду

$$
\mathrm{F}(\mathrm{x})=\sum_{\mathrm{i}=1}^{\mathrm{m}} \mathrm{c}_{\mathrm{i}} \mathrm{f}_{\mathrm{i}}(\mathrm{x}),
$$

де $\mathrm{c}_{\mathrm{i}}, \mathrm{i}=\overline{1, \mathrm{~m}}$ - коефіцієнти важливості вихідних цілей, що відображають міру наданої переваги ОПР. Покладають, що коефіцієнти нормовані тим чи іншим способом. Зазвичай застосовують нормування у формі

$$
\sum_{\mathrm{i}=1}^{\mathrm{m}} \mathrm{c}_{\mathrm{i}}=1 .
$$

Зазначимо, що для функцій $\mathrm{f}_{\mathrm{i}}(\mathrm{x})>0, \mathrm{i}=\overline{1, \mathrm{~m}}$, замість адитивної функції $\mathrm{F}(\mathrm{x})$ можна використовувати мультиплікативну функцію $\mathrm{F}_{\mathrm{M}}(\mathrm{x})$ вигляду

$$
\mathrm{F}_{\mathrm{M}}(\mathrm{x})=\prod_{\mathrm{i}=1}^{\mathrm{m}}\left(\mathrm{f}_{\mathrm{i}}(\mathrm{x})\right)^{\mathrm{c}_{\mathrm{i}}} \text {. }
$$

Унаслідок згортки (4) або (6), задача розкриття невизначеності цілей, подана у вигляді багатоцільової задачі оптимізації (2)-(3), зводиться до одноцільової стандартної задачі математичного програмування $\mathrm{F}(\mathrm{x}) \rightarrow \max \quad$ за наявності обмежень.

Цей метод досить широко застосовується на практиці. Однак проблемними моментами його застосування є:

вибір коефіцієнтів важливості $\mathrm{c}_{\mathrm{i}}, \mathrm{i}=\overline{1, \mathrm{~m}}$ вихідних цілей $\mathrm{f}_{\mathrm{i}}(\mathrm{x}), \mathrm{i}=\overline{1, \mathrm{~m}}$ значною мірою суб'єктивний, а отже, не виключені принципові помилки і прорахунки у їх виборі;

розв'язання оптимізаційної задачі для $\mathrm{F}(\mathrm{x})$ не означає, що досягнуто раціональних значень для всіх заданих цілей. У згортках (4) і (6) недостатне значення однієї цільової функції може бути компенсоване збільшенням значень іншої цільової функції. Більше того, змінюючи значення коефіцієнтів важливості, можна одержати серію різних значень $\mathrm{x}$, для яких функція $\mathrm{F}(\mathrm{x})$ має те саме значення.

Отже, фактично невизначеність цілей у такій постановці задачі не буде розв'язана необхідною для практики мірою, оскільки згортка не дає однозначного раціонального варіанта значень х .

Метод технічних обмежень.

Згідно цього методу задача (2)-(3) зводиться до одного з варіантів.

Варіант 1. Для кожного значення х будується функція

$$
F_{1}(x)=\min _{i \in[1, m]} \frac{f_{i}(x)}{f_{i}^{*}}
$$

i знаходяться такі значення $\mathrm{x}^{0}$, що відповідають умові $\mathrm{F}_{1}\left(\mathrm{x}^{0}\right)=\max _{\mathrm{x} \in \mathrm{D}} \mathrm{F}_{1}(\mathrm{x})$.

За такого формулювання задачі гарантовано, що у найгіршому випадку буде забезпечено максимальне значення $\mathrm{F}_{1}(\mathrm{x})$.

Така задача забезпечення $\epsilon$ максимінною задачею оптимізації.

Варіант 2. Для кожного значення х будується функція

$$
F_{2}(x)=\max _{i \in[1, m]} \frac{f_{i}(x)}{f_{i}^{*}}
$$

i знаходяться такі значення $\mathrm{x}^{0}$, що відповідають умові $\mathrm{F}_{2}\left(\mathrm{x}^{0}\right)=\min _{\mathrm{x} \in \mathrm{D}} \mathrm{F}_{2}(\mathrm{x})$.

За такого формулювання задачі гарантовано, що у найгіршому випадку буде забезпечено 
мінімальне значення $\mathrm{F}_{2}(\mathrm{x})$.

Така задача забезпечення $€$ мінімаксною задачею оптимізації.

Відмінність варіантів 1 і 2 полягає в тому, що вони стосуються різних умов оптимальності.

Технологічно застосування методу технічних обмежень до задачі

$$
\mathrm{f}_{1}(\mathrm{x}) \rightarrow \max _{\mathrm{x} \in \mathrm{D}}, \mathrm{f}_{2}(\mathrm{x}) \rightarrow \max _{\mathrm{x} \in \mathrm{D}}
$$

за умов

$$
\mathrm{f}_{1}(\mathrm{x}) \leq \mathrm{f}_{1}^{*}, \mathrm{f}_{2}(\mathrm{x}) \leq \mathrm{f}_{2}^{*},
$$

яка $\epsilon$ частковим випадком задачі (2)-(3), можна оцінити 3 рис. 3.

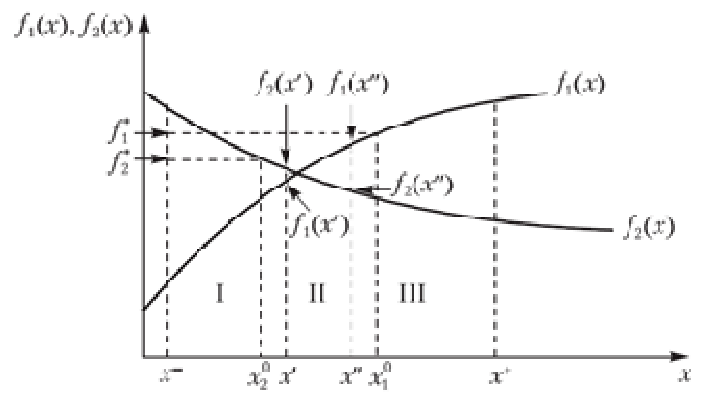

Рис. 3. Приклад розв'язання задачі розкриття невизначеності цілей

На рис. 3 область Парето являє собою проміжок $\left[\mathrm{x}_{2}^{0}, \mathrm{x}_{1}^{0}\right]$. Ї̈і межі визначають умови

$$
\mathrm{f}_{2}\left(\mathrm{x}_{2}^{0}\right)=\mathrm{f}_{2}^{*}, \mathrm{f}_{1}\left(\mathrm{x}_{2}^{0}\right)<\mathrm{f}_{1}^{*} ; \mathrm{f}_{1}\left(\mathrm{x}_{1}^{0}\right)=\mathrm{f}_{1}^{*}, \mathrm{f}_{2}\left(\mathrm{x}_{1}^{0}\right)<\mathrm{f}_{2}^{*}
$$

а при

$\mathrm{x}_{2}^{0}<\mathrm{x}<\mathrm{x}_{1}^{0}, \mathrm{x} \in\left(\mathrm{x}_{2}^{0}, \mathrm{x}_{1}^{0}\right), \mathrm{f}_{1}(\mathrm{x}) \leq \mathrm{f}_{1}^{*}, \mathrm{f}_{2}(\mathrm{x}) \leq \mathrm{f}_{2}^{*}$.

Далі для відшукання раціонального компромісу в області Парето поступають так.

Знаходяться точки $\mathrm{x}^{\prime}, \mathrm{x}^{\prime \prime} \in\left[\mathrm{x}_{2}^{0}, \mathrm{x}_{1}^{0}\right]$, у яких

$$
\begin{aligned}
& \frac{\mathrm{f}_{2}\left(\mathrm{x}^{\prime}\right)}{\mathrm{f}_{2}^{*}}>\frac{\mathrm{f}_{1}\left(\mathrm{x}^{\prime}\right)}{\mathrm{f}_{1}^{*}}, \\
& \frac{\mathrm{f}_{2}\left(\mathrm{x}^{\prime \prime}\right)}{\mathrm{f}_{2}^{*}}<\frac{\mathrm{f}_{1}\left(\mathrm{x}^{\prime \prime}\right)}{\mathrm{f}_{1}^{*}}
\end{aligned}
$$

i на множині $\left[\mathrm{x}^{\prime} ; \mathrm{x}^{\prime \prime}\right]$ знаходиться точка $\mathrm{x}=\mathrm{x}^{\prime \prime \prime}$, в якій

$$
\frac{\mathrm{f}_{2}\left(\mathrm{x}^{\prime \prime \prime}\right)}{\mathrm{f}_{2}^{*}}=\frac{\mathrm{f}_{1}\left(\mathrm{x}^{\prime \prime \prime}\right)}{\mathrm{f}_{1}^{*}} .
$$

Точка $\mathrm{x}=\mathrm{x}^{\prime \prime \prime}$ i визначає раціональний компроміс для задачі (9)-(10).

Проблемними моментами застосування описаного методу є:

розглянутий підхід не дозволяе кількісно зіставити різні варіанти допустимих розв'язків із множини Парето, наприклад, не можна сказати, який із варіантів найкращий у точках $\mathrm{x}^{\prime} \mathrm{i} \mathrm{x}^{\prime \prime}$;

наведений підхід не дає однозначної відповіді на питання про раціональний компроміс i $\mathrm{y}$ випадку, коли область Парето складається 3 кількох проміжків чи інтервалів.

Метод послідовного розкриття невизначеності цілей.

Суть методу i структура обчислювального алгоритму його реалізації детально наведена в роботі [2].
Метод може застосуватись до задачі, математичне формулювання якої має наступний вигляд.

Відомі вимоги та обмеження до проектованого виробу. Вимоги визначають бажані значення показників якості виробу, поданих у формі допустимих інтервалів змін для кожного показника, і утворюють множину

$$
\mathrm{Q}_{0}=\left\{\mathrm{Q}_{\mathrm{i}} \mid \mathrm{Q}_{\mathrm{i}}^{-} \leq \mathrm{Q}_{\mathrm{i}} \leq \mathrm{Q}_{\mathrm{i}}^{+}, \mathrm{i}=\overline{1, \mathrm{~m}}\right\},
$$

де $\mathrm{Q}_{\mathrm{i}}$ кількісно характеризує певний показник якості.

Задано обмеження для конструктивних, технологічних, економічних, експлуатаційних та інших показників виробу, які подано у вигляді

$$
x_{j}^{-} \leq x_{j} \leq x_{j}^{+}, j=\overline{1, n}
$$

й утворюють множину обмежень $\mathrm{x}_{0}=\left\{\mathrm{x}_{\mathrm{j}} \mid \mathrm{x}_{\mathrm{j}}^{-} \leq \mathrm{x}_{\mathrm{j}} \leq \mathrm{x}_{\mathrm{j}}^{+}, \mathrm{j}=\overline{1, \mathrm{n}}\right\}$, де $\mathrm{x}_{\mathrm{j}}$ визначає один із зазначених вище показників. Відомі залежності

$$
Q_{i}=f_{i}(x), i=\overline{1, m} ; x=\left\{x_{j} \mid j=\overline{1, n}\right\} .
$$

Потрібно знайти таке значення $\mathrm{x}^{*}$ вектора $\mathrm{x}$, за якого для кожного показника якості $\mathrm{Q}_{\mathrm{i}}$ виконується умова

$$
\mathrm{Q}_{\mathrm{i}}^{*} \rightarrow \max _{\mathrm{x} \in \mathrm{X}_{0}} \mathrm{f}_{\mathrm{i}}(\mathrm{x}), \mathrm{i}=\overline{1, \mathrm{~m}} .
$$

Застосування методу послідовного розкриття невизначеності цілей до задачі (2)-(3) обмежено придатне, оскільки у загальному випадку у досліджуваній задачі аргумент належить деякій неперервній множині, а в аналізованому методі аргумент є дискретним.

Розкриття невизначеності цілей зведенням вихідної задачі до системи рівнянь.

У цьому методі припускається, що для кожної цілі потрібно виконати умови

$$
\mathrm{f}_{\mathrm{i}}(\mathrm{x})=\mathrm{f}_{\mathrm{i}}^{*}, \mathrm{i}=\overline{1, \mathrm{~m}} \text {. }
$$

Оскільки ж ці умови для різних функцій $\mathrm{f}_{\mathrm{i}}(\mathrm{x})$ виконуються не за однакових, а за суттєво різних значень х (як приклад, див. рис. 4), то виникає потреба спільного аналізу всіх цілей щодо оцінювання відмінності реалізованих обмежень від заданих для кожної функції $\mathrm{f}_{\mathrm{i}}(\mathrm{x})$.

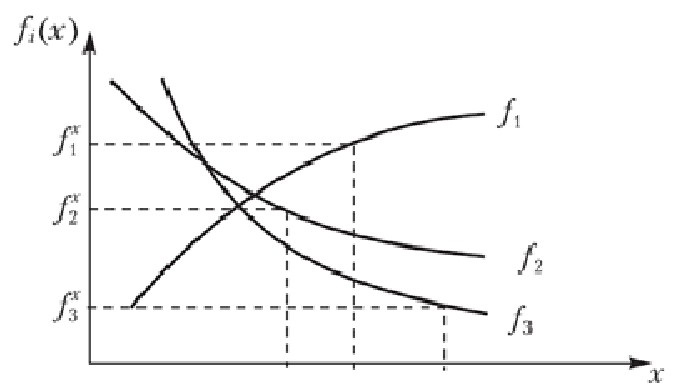

Рис. 4. Розкриття невизначеності цілей на основі системи рівнянь

Сукупність вихідних обмежень подається у вигляді системи рівнянь

$$
f_{i}(x)-f_{i}^{*}=0, i=\overline{1, m} .
$$

Оскільки у практичних задачах $\mathrm{x}$ - це вектор $\left(\mathrm{x}=\left\{\mathrm{x}_{1}, \mathrm{x}_{2}, \ldots, \mathrm{x}_{\mathrm{j}}, \ldots, \mathrm{x}_{\mathrm{n}}\right\}, \mathrm{j}=\overline{1, \mathrm{n}}\right)$, то формулу (12) 
можна розглядати як систему $3 \mathrm{~m}$ рівнянь $3 \mathrm{n}$ невідомими $\mathrm{x}_{1}, \mathrm{x}_{2}, \ldots, \mathrm{x}_{\mathrm{n}}$. Очевидно, що спосіб розв'язання цієї системи залежить від співвідношення між $\mathrm{m}$ та $\mathrm{n}$. Можливі такі випадки: $\mathrm{m}=\mathrm{n}, \mathrm{m}<\mathrm{n}$ та $\mathrm{m}>\mathrm{n}$.

Найпростіший варіант $\mathrm{m}=\mathrm{n}$, для якого $\mathrm{y}$ деяких випадках можна розкрити невизначеність цілі, розв'язавши систему (12) одним із відомих методів [9]. При цьому точно забезпечуватиметься умова (11) для кожної i -ї цілі. Однак така ситуація на практиці зазвичай виняткова. Більше того, навіть за $\mathrm{m}=\mathrm{n}$ не завжди можна розв'язати систему (12) через суперечливість цілей

У випадку $\mathrm{m}<\mathrm{n}$ система (12) перевизначена, що дає змогу довільно варіювати деякі компоненти вектора $\mathrm{x}$. У загальному випадку максимальна кількість таких компонент може дорівнювати $\mathrm{m}-\mathrm{n}$. Найпростішим прийомом розв'язання задачі для $\mathrm{m}<\mathrm{n}$ можна вважати апріорне задання значень деяких змінних на основі інтуїції і досвіду ОПР або на підставі аналізу відповідних показників відомих прототипів виробів і проектів. У підсумку одержуємо, що система переходить до розглянутого варіанта $\mathrm{m}=\mathrm{n}$. Варіюючи компонентами вектора $\mathrm{x}$, можна одержати різні умови розкриття невизначеності цілей. Далі з отриманих варіантів вибирають раціональні розв'язки. Однак на практиці зазначений випадок трапляється вкрай рідко, оскільки кількість вимог (тобто цілей $\mathrm{f}_{\mathrm{i}}(\mathrm{x})$ ) перевищує кількість параметрів (тобто компонент вектора х ).

У випадку $\mathrm{m}>\mathrm{n}$ система (12) несумісна, тобто не можна знайти такі значення $\mathrm{x}_{1}, \mathrm{x}_{2}, \ldots, \mathrm{x}_{\mathrm{n}}$, щоб виконувалися умови (11) для всіх $\mathrm{i}=\overline{1, \mathrm{~m}}$. Тому прийнято, що в алгебраїчному сенсі несумісна система рівнянь не має розв'язків. Слід також зазначити, що у загальному випадку функції $\mathrm{f}_{\mathrm{i}}(\mathrm{x}), \mathrm{i}=\overline{1, \mathrm{~m}}$ нелінійні, i система (12) - несумісна система нелінійних рівнянь.

Методи розв'язування несумісних систем рівнянь вигляду (12) розроблено в теорії наближення функцій $[10,11]$. Для такої системи через перевищення кількості рівнянь $\mathrm{m}$ порівняно 3 кількістю змінних $\mathrm{n}$ принципово неможливо одержати розв'язок, який забезпечить виконання умови (12). Тому розв'язання системи зводиться до мінімізації функцій

$$
\widetilde{f}_{i}(x)=f_{i}(x)-f_{i}^{*}, i=\overline{1, m} .
$$

Якість розв'язку цієї системи характеризується середньоквадратичним, чебишевським, середньостепеневим та іншими критеріями. Зазначимо, що найдоцільніший із практичного погляду - чебишевський критерій наближення функцій. Для цього критерію чебишевська задача наближення системи (12) полягає у знаходженні такого $\mathrm{x}^{0}=\left(\mathrm{x}_{1}^{0}, \mathrm{x}_{2}^{0}, \ldots, \mathrm{x}_{\mathrm{n}}^{0}\right), \quad$ для якого максимальна нев'язка

$$
\Delta=\max _{\mathrm{i} \in[1, \mathrm{~m}]}\left|\mathrm{f}_{\mathrm{i}}(\mathrm{x})-\mathrm{f}_{\mathrm{i}}^{*}\right|,
$$

взята за міру чебишевського наближення системи (12), інакше кажучи, за міру чебишевського наближення системи функцій $\widetilde{\mathrm{f}}_{\mathrm{i}}(\mathrm{x}), \mathrm{i}=\overline{1, \mathrm{~m}}$, була б мінімально можливою:

$$
\Delta^{0}=\min _{\mathrm{x}} \Delta .
$$

Виконання умов (15) означає, що при $\mathrm{x}=\mathrm{x}^{0}$ максимальний відхил від нульових значень системи функцій $\tilde{\mathrm{f}}_{\mathrm{i}}(\mathrm{x})$ буде мінімально можливим. Вибір будь-якого значення $\mathrm{x} \neq \mathrm{x}^{0}$ приведе до того, що $\Delta>\Delta^{0}$. Величина $\mathrm{x}^{0}-$ це аргумент, який забезпечує мінімізацію максимальної нев'язки, тобто

$$
\mathrm{x}^{0}=\arg \min _{\mathrm{x} \in\left[\mathrm{x}^{-}, \mathrm{x}^{+}\right] \mathrm{max} \in \mathrm{i}, \mathrm{m}}\left|\mathrm{f}_{\mathrm{i}}(\mathrm{x})-\mathrm{f}_{\mathrm{i}}^{*}\right| .
$$

Перевага цього підходу до розкриття невизначеності цілей полягає в тому, що поряд зі знаходженням $\mathrm{x}^{0} \epsilon$ можливість визначити абсолютні відхили всіх функцій $\mathrm{f}_{\mathrm{i}}(\mathrm{x})$ від їх заданих значень $\mathrm{f}_{\mathrm{i}}^{*}$, тобто визначити відхил не тільки для найгіршого випадку, але й для всіх інших цілей.

Застосування цього методу пов'язане також 3 окремими проблемними моментами. До числа таких можна віднести наступне.

1. $\mathrm{y}$ загальному випадку, коли $\mathrm{f}_{\mathrm{i}}(\mathrm{x})$ нелінійні, задачі (14), (15) для системи (12) можуть мати багато розв'язків.

2. Крім Чебишевського, можна використовувати й інші критерії. Зокрема, найзагальнішим із них $\epsilon$ середньостепеневий критерій. Позначимо

Приймемо

$$
\Delta f_{i}=\left(f_{i}(x)-f_{i}^{*}\right) .
$$

$$
\Delta \mathrm{f}_{(\mathrm{q})}=\left[\sum_{\mathrm{i}=1}^{\mathrm{m}}\left(\Delta \mathrm{f}_{\mathrm{i}}\right)^{\mathrm{q}}\right]^{1 / \mathrm{q}},
$$

де $\Delta \mathrm{f}_{\mathrm{i}}, \Delta \mathrm{f}_{(\mathrm{q})}-$ відповідно міра нев'язки $\mathrm{i}$ середньостепеневий критерій наближення; q степінь середньостепеневого критерію. На практиці найпоширеніше значення $\mathrm{q}=2$, а відповідний критерій називають середньоквадратичним

$$
\Delta f_{(2)}=\left[\sum_{i=1}^{m}\left(\Delta f_{i}\right)^{2}\right]^{1 / 2}=\sqrt{\sum_{i=1}^{m}\left(\Delta f_{i}\right)^{2}} .
$$

У разі використання критеріїв (18), (19) задача наближення для системи (12) полягає у визначенні такого значення $\mathrm{x}^{0}$, для якого

$$
\begin{aligned}
& \Delta \mathrm{f}_{(\mathrm{q})}^{0}=\left\{\sum_{\mathrm{i}=1}^{\mathrm{m}}\left[\Delta \mathrm{f}_{\mathrm{i}}\left(\mathrm{x}^{0}\right)\right]^{\mathrm{q}}\right\}^{1 / \mathrm{q}}=\min _{\mathrm{x} \in\left[\mathrm{x}^{-}, \mathrm{x}^{+}\right]} \Delta \mathrm{f}_{\mathrm{q}} ; \\
& \Delta \mathrm{f}_{(2)}^{0}=\left\{\sum_{\mathrm{i}=1}^{\mathrm{m}}\left[\Delta \mathrm{f}_{\mathrm{i}}\left(\mathrm{x}^{0}\right)\right]^{2}\right\}^{1 / 2}=\min _{\mathrm{x} \in\left[\mathrm{x}^{-}, \mathrm{x}^{+}\right]} \Delta \mathrm{f}_{2} .
\end{aligned}
$$

Принциповою відмінністю чебишевського i середньостепеневого (при $\mathrm{q}<\infty$ ) критеріїв $\epsilon$ наступне. Чебишевський критерій гарантує, що абсолютний відхил будь-якої функції $\mathrm{f}_{\mathrm{i}}(\mathrm{x})$ від заданого значення $\mathrm{f}_{\mathrm{i}}^{*}$, якщо обрано $\mathrm{x}=\mathrm{x}^{0}$, не перевищуватиме значення $\Delta^{0}$.

Середньостепеневий критерій гарантує, що в 
середньому (для відповідного степеня) відхил усіх функцій не перевищуватиме значення $\Delta_{(q)}^{0}$. Але він не гарантує, що окремі функції не відхилятимуться на наперед задане значення $\Delta_{i}^{0}$. Тому середньостепеневий критерій незастосовний у задачах, де критичним є абсолютний відхил певних показників і характеристик.

3. Наведені критерії у формі (15) для чебишевського наближення і у формі (17) або (18) для середньостепеневого критерію зорієнтовано на умову, за якої всі цілі є рівнозначними. На практиці ця умова рідко виконується, тобто найчастіше $є$ перевага цілей.

Авторський метод розв'язування задачі розкриття невизначеності циілей $i$ оиінка його ефективності.

Аналіз існуючих підходів і методів розкриття невизначеності цілей, а також проблемних питань, що мають місце при їх застосуванні, які проведені вище, дозволяють зробити наступні висновки:

кожен із методів адаптований на окремий клас задач;

кожен із методів має ряд недоліків, що не дозволяють їх застосовувати в якості універсального інструменту розв'язування досліджуваної у роботі задачі;

застосування наведених методів у загальному випадку не забезпечує однакових розв'язків однієї і тієї ж задачі;

в основі кожного 3 методів міститься ідея, що реалізує фізичний зміст процесу розв'язування задачі;

у разі мінімізації суб'єктивного впливу на результат розв'язування задачі (2)-(3) доцільним є застосування різних ідей, що характерні для кожного 3 наведених методів.

Проведений аналіз і наведені висновки дозволили авторам висунути гіпотезу про те, що поєднання описаних методів для розв'язування задачі (2)-(3) може дозволити усунути характерні недоліки.

Суть авторського методу полягає в наступному.

При розв'язуванні досліджуваної задачі пропонується реалізувати два етапи: пошук області Парето (виключення 3 аналізу заздалегідь неприйнятних варіантів розв'язків); розв'язування багатоцільової задачі в області Парето (прийнятних варіантів розв'язків).

При реалізації першого етапу пропонується здійснити пошук області Парето $\left[\mathrm{x}_{1} ; \mathrm{x}_{\mathrm{r}}\right]$ як і в випадку застосування методу технічних обмежень.

Для реалізації другого етапу пропонується застосувати кожен із наведених методів i в разі співпадання результатів в якості розв'язку прийняти отриманий будь-яким із них. У разі ж неспівпадання результатів пошук розв'язку пропонується здійснювати на області Парето $\left[\mathrm{x}_{1} ; \mathrm{x}_{\mathrm{r}}\right]$ шляхом іiі подальшого звуження. При цьому особливість звуження полягає у змінності кроку звуження як для кожної окремої ітерації, так і для кожної 3 меж області Парето. Величина змінності кроку залежить від виду функцій $\mathrm{f}_{\mathrm{i}}(\mathrm{x}), \mathrm{i}=\overline{1, \mathrm{~m}}$ i може бути знайдена за допомогою наступного алгоритму.

1. За початкові $x_{1}$ та $x_{r}$ беруться крайні ліва $i$ права точки області Парето, відповідно.

2. Знаходяться точки максимуму кожної функції на початковій множині Парето $\left(\left[\mathrm{x}_{1} ; \mathrm{x}_{\mathrm{r}}\right]\right)$.

3. Розраховується крок звуження $\mathrm{d}_{1}$ для лівої межі області Парето (для точки $\mathrm{x}_{1}$ ):

1) $\mathrm{y}$ точці $\mathrm{x}_{1}$ знаходяться значення модуля похідної кожної функції: $\left|\mathrm{f}_{\mathrm{i}}^{\prime}\left(\mathrm{x}_{1}\right)\right|$;

2) знаходиться крок звуження $\mathrm{d}_{1}$ як модуль алгебраїчної суми модулів похідних функцій у точці $\mathrm{x}_{1}\left(\left|\mathrm{f}_{\mathrm{i}}^{\prime}\left(\mathrm{x}_{1}\right)\right|\right)$. При цьому, якщо $\mathrm{x}_{1}<\mathrm{x}_{\max }$, де $\mathrm{x}_{\max }-$ точка, в якій функція $\mathrm{f}_{\mathrm{i}}$ досягає максимуму, то $\left|\mathrm{f}_{\mathrm{i}}^{\prime}\right|$ додається, а якщо $\mathrm{x}_{1}>\mathrm{x}_{\max }$, то $\left|\mathrm{f}_{\mathrm{i}}^{\prime}\right|$ віднімається.

4. Розраховується крок звуження $\mathrm{d}_{\mathrm{r}}$ для правої межі області Парето (для точки $\mathrm{x}_{\mathrm{r}}$ ):

1) $\mathrm{y}$ точці $\mathrm{x}_{\mathrm{r}}$ знаходяться значення модуля похідної кожної функції: $\left|\mathrm{f}_{\mathrm{i}}^{\prime}\left(\mathrm{x}_{\mathrm{r}}\right)\right|$;

2) знаходиться крок звуження $d_{r}$ як модуль алгебраїчної суми модулів похідних функцій у точці $\mathrm{x}_{\mathrm{r}}\left(\left|\mathrm{f}_{\mathrm{i}}^{\prime}\left(\mathrm{x}_{\mathrm{r}}\right)\right|\right)$. При цьому, якщо $\mathrm{x}_{\mathrm{r}}>\mathrm{x}_{\max }$, де $\mathrm{x}_{\max }$ - точка, в якій функція $\mathrm{f}_{\mathrm{i}}$ досягає максимуму, то $\left|\mathrm{f}_{\mathrm{i}}^{\prime}\right|$ додається, а якщо $\mathrm{x}_{\mathrm{r}}<\mathrm{x}_{\max }$, то $\left|\mathrm{f}_{\mathrm{i}}^{\prime}\right|$ віднімається.

5. Звужена множина Парето розраховується як $\left[\mathrm{x}_{1}+\mathrm{d}_{1} \cdot \Delta ; \mathrm{x}_{\mathrm{r}}-\mathrm{d}_{\mathrm{r}} \cdot \Delta\right]$, де $\Delta-$ наперед заданий крок звуження, і позначається знову у вигляді $\left[\mathrm{x}_{1} ; \mathrm{x}_{\mathrm{r}}\right]$.

6. Якщо $\left|\mathrm{x}_{1}-\mathrm{x}_{\mathrm{r}}\right|>\Delta$, здійснюється перехід до кроку 3, якщо $\left|\mathrm{x}_{1}-\mathrm{x}_{\mathrm{r}}\right|<\Delta$, то за точку раціонального компромісу приймається $\mathrm{x}_{1}$.

Для оцінки ефективності запропонованого методу розв'язування задачі розкриття невизначеності цілей авторами було опрацьовано відповідний програмний додаток. Середовищем його розробки було обрано Microsoft Visual Studio 2017, як одне 3 найпотужніших середовищ розробки для мови С\# [12-14].

Результати роботи додатку, що опрацьований авторами та відповідає наведеному методу для різних функцій і різної кількості функцій, можуть бути оцінені з рис. 5-7.

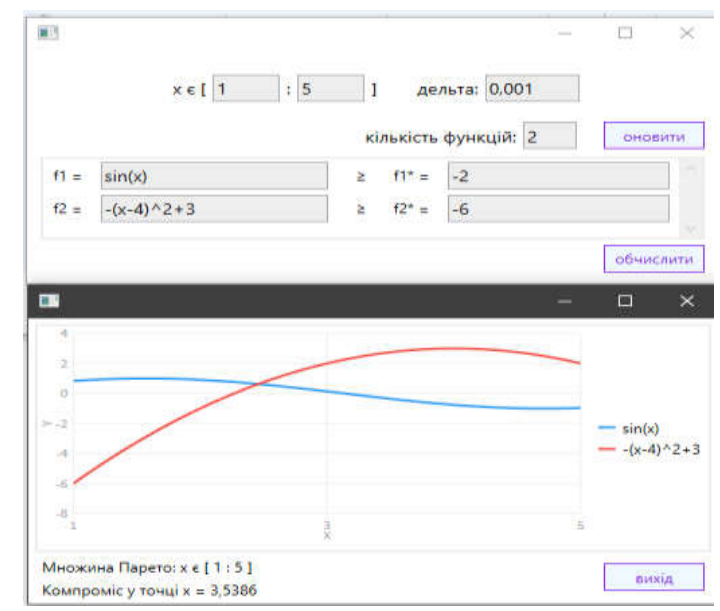

Рис. 5. Вікна програми з умовами задачі і результатами ії розв'язування у випадку двох нелінійних функцій 


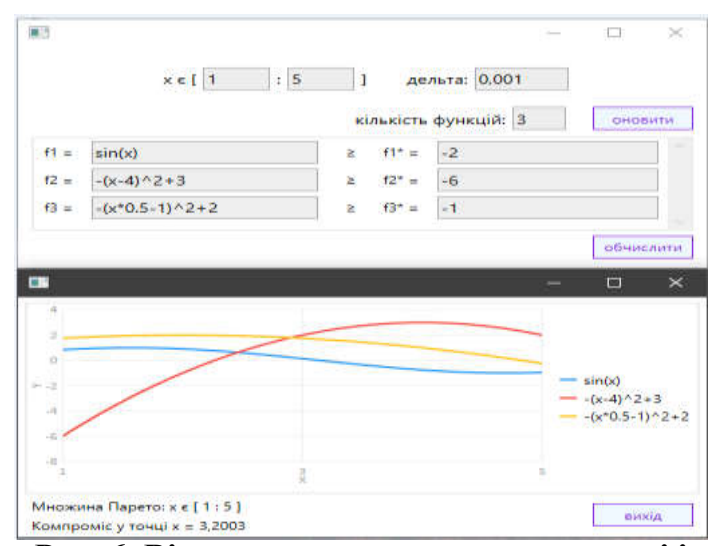

Рис. 6. Вікна програми з умовами задачі і результатами її розв'язування у випадку трьох нелінійних функцій

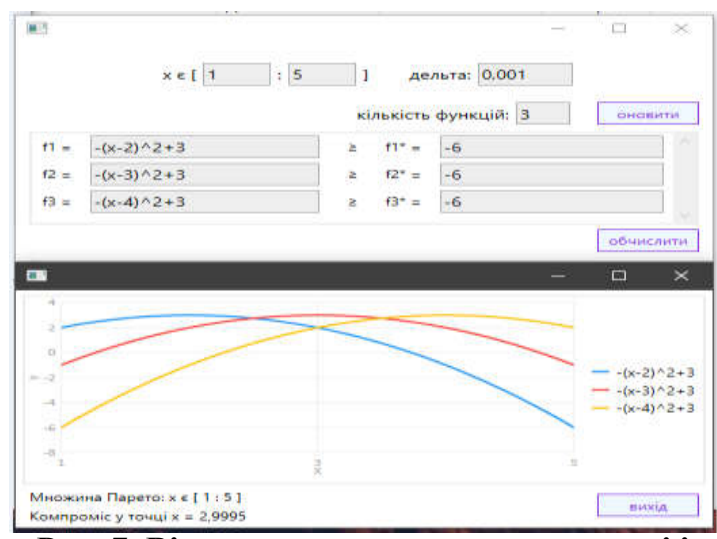

Рис. 7. Вікна програми з умовами задачі i результатами її розв'язування у випадку трьох нелінійних функцій

Слід зазначити, що межами застосування Лimepamypa

1. Нагель Э., Ньюман Д. Теорема Геделя. - М.: Знание, 1970. - 63 с. 2. Згуровський М. 3., Панкратова Н. Д. Основи системного аналізу. - К.: Видавнича група ВНV, 2007. - 544 с. 3. Моисеев Н. Н. Математические задачи системного анализа. - М.: Наука, 1981. - 488 с. 4. Саати Т. Принятие решений. Метод анализа иерархий. - М.: Радио и связь, 1993. - 278 с. 5. Вентцель Е. С. Исследование операций. М.: Советское радио, 1972. - 552 с. 6. Боровик О.В., Боровик Л.В. Дослідження операцій в економіці: Навчальний посібник. - К.: Центр учбової літератури, 2007. - 424 с. 7. Сергиенко И. В. Математические модели и методы решения задач дискретной оптимизации. - К.: Наук. думка, 1985. - 384 с. 8. Васильев Ф. П. Численные методы решения экстремальных задач. - М.: Наука, 1988. 552 с. 9. Боровик О. В., Боровик Л. В., Матохнюк Л. О. Вища математика:: елементи лінійної і векторної алгебри. Аналітична геометрія. Частина 1: навчальний посібник. - авторського методу є:

задачі виду (2)-(3) розкриття невизначеності цілей, які задаються функціями однієї змінної;

випадки, коли кількість функцій $\mathrm{f}_{\mathrm{i}}(\mathrm{x}), \mathrm{i}=\overline{1, \mathrm{~m}}$ довільна (скінченна);

випадки, коли задача (2)-(3) має різні розв'язки, що отримуються принаймні двома методами 3 числа існуючих, які проаналізовані в даній роботі;

випадки, при яких область Парето являє собою один проміжок чи інтервал.

\section{Висновки й перспективи подальших досліджень}

Таким чином, за результатами проведеного дослідження у роботі: визначено клас задач розкриття невизначеності цілей, що визначаються функціями однієї змінної; здійснено аналіз існуючих підходів i методів розкриття невизначеності цілей, а також чітко окреслено коло проблемних питань, що мають місце при їх застосуванні; запропоновано авторський метод розв'язування визначеного класу задач у визначених межах застосування; здійснено його алгоритмізацію і програмування, а також оцінено застосування на різних прикладах.

Напрямками подальших досліджень авторам вбачається розширення наведеного методу на досліджуваний клас задач за умови, коли область Парето відсутня.

Хмельницький: Видавництво НАДПСУ, 2015. - 488 с. 10. Курилин Б.И. К решению чебышевской задачи приближения для несовместной системы нелинейных уравнений // Журнал вычислительной математики и математической ф изики. -0 1970. Т. 10. - № 1. С. 3-14. 11. Ремез Е.Я. Основы численных методов чебышевского приближения. - К.: Наук. думка, 1969. - 624 с. 12. Рамбо Дж., Блаха M. UML 2.0 Обьектно-ориентированое моделирование и разработка / Дж. Рамбо, М. Блаха; - 2-е изд. - СПб.: Питер, 2007. - 544 с. 13. Мак-Дональд, Мэтью. WPF 4: Windows Presentation Foundation в .NET 4.0 с примерами на С\# 2010 для профессионалов: Пер. с англ. М.: ООО "И.Д. Вильяме", 2011. - 1024 с. 14. Johnson Bruse Professional Visual Studio 2013 / Bruse Johnson - Indianapolis: John Wiley \& Sons, Inc., 2014. - 1048 p.

\title{
МЕТОД ПОИСКА РАЦИОНАЛЬНОГО КОМПРОМИССА В ОДНОМ КЛАССЕ ЗАДАЧ МНОГОКРИТЕРИАЛЬНОЙ ОПТИМИЗАЦИИ ПРИ РАСКРЫТИИ НЕОПРЕДЕЛЕННОСТИ ЦЕЛЕЙ, КОТОРЫЕ ЗАДАЮТ ФУНКЦИИ ОДНОЙ ПЕРЕМЕННОЙ
}

\author{
${ }^{1}$ Олег Васильевич Боровик (докт. техн. наук, профессор) \\ ${ }^{1}$ Людмила Владимировна Боровик (канд. психол. наук, доцент) \\ ${ }^{2}$ Николай Витальевич Красовский
}

${ }^{1}$ Национальная академия Государственной пограничной службы Украины имени Богдана Хмельницкого, Хмельницкий, Украина

${ }^{2}$ Хмельницкий национальный университет, Хмельницкий, Украина 
Для значительного класса формализованных задач системного анализа важной проблемой является раскрытие неопределенностей. Формально задачи раскрытия неопределенностей в системном анализе и теории

исследования операций во многом похожи. Однако есть и принципиальные отличия, заключаючщеся в следуюшем. Задачи исследования операчий имеют большую степень формализащии, поскольку в них обычно априори задано все ограничения, предположения, исходнье данные и математические модели. В задачах системного анализа часть ограничений, предположений и исходных данных заранее не изучено, информацию о них уточняют в процессе формализачии и решения задачи. На сегодня остается актуальной задача раскрытия неопределенности иелей 8 многокритериальньх задачах принятия решений, которые сводятся к задачам системного анализа "мягкой формализащии". Одной из таких является задача поиска ращионального компромисса при многокритериальной оптимизации для совокупности функций одной переменной.

В работе: определен класс задач раскрытия неопределенности целей, определяемых функциями одной переменной; осуществлен анализ существующих подходов и методов раскрытия неопределенности иелей, а также четко определен круг проблемных вопросов, которые имеют место при их применении; предложен авторский метод решения определенного класса задач в определенных пределах применения; осуществлена его алгоритлизация и программирование, а также оценено применение на различных примерах.

Ключевые слова: системньій анализ; многокритериальная оптимизащия; неопределенность целей; область Парето; формализаџия; рацииональньій компромисс.

\title{
RATIONAL COMPROMISE SEARCHING METHOD IN ONE CLASS OF MULTIOBJECTIVE OPTIMIZATION PROBLEM IN EVALUATION OF INDETERMINATE OBJECTIVES SET BY THE FUNCTIONS OF ONE VARIABLE
}

\author{
${ }^{1}$ Oleh V. Borovyk (Doctor of Engineering Science, Professor) \\ ${ }^{1}$ Liudmyla V. Borovyk (Candidate of Psychological Sciences, Associate Professor) \\ ${ }^{2}$ Mykola V. Krasovsky
}

${ }^{1}$ Bohdan Khmelnytskyii National Academy of the State Border Guard Service of Ukraine, Khmelnytskyii, Ukraine

${ }^{2}$ Khmelnytskyi National University, Khmelnytskyi, Ukraine

Evaluation of indeterminate forms is a current problem for a significant class of formalized system analysis tasks. Formally, the problems of indeterminate forms evaluation in the system analysis and the operations research theory are largely similar. However, there are also fundamental differences that lie in the following. The problems of operations research have a greater degree of formalization, since they usually a priori provide all the restrictions, conditions, outcoming data and mathematical models. In system analysis problems, part of restrictions, conditions, outcoming data have not been studied in advance, the information about them is refined in the process of problem formalization and solving. Presently, the task of indeterminate objectives evaluation in multiobjective decision making problems, which are reduced to "soft formal characterization" system analysis problems, remains topical. One of them is the problem of finding a rational compromise in multiobjective optimization for a totality of one variable functions.

The work: determines the class of indeterminate objectives evaluation problems, determined by the functions of one variable; analyzes existing approaches and methods of indeterminate objectives evaluation; clearly outlines the range of problematic issues that occur in their application. The authors' method of solving a certain class of problems in the defined limits of application has been proposed; its algorithmization and programming as well as its application evaluation based on various examples have been carried out.

Keywords: system analysis, multiobjective optimization, uncertainty of objectives, Pareto region, formalization, rational compromise.

\section{References}

1. Nagel E., Newman D. Theorem of Gödel. [Teorema Hedelia] - M.: Znanie, 1970. - 63 p. 2. Zgurovsky M. Z., Pankratova N. D. Fundamentals of System Analysis. [Osnovy systemnoho analizu] - K.: BHV Publishing group, 2007. - 544 p. 3. Moiseev N. N. Mathematical problems of system analysis. [Matematycheskye zadachy systemnoho analyza] - M.: Nauka, 1981. - 488 p. 4. Saati T. Decision making. Hierarchies analysis method. [Pryniatye reshenyi. Metod analyza yerarkhyi] - M.: Radio and Communications, 1993. - 278 p. 5. Ventzel E. S. Study of operations. [Issledovanie operatsyi]. - M.: Soviet Radio, 1972. - 552 p. 6. Borovyk O.V., Borovyk L.V. Study of Operations in Economics: Textbook. [Doslidzhennia operatsii v ekonomitsi: Navchalnyi posibnyk]. - K.: Center for Educational Literature, 2007. - 424 p. 7. Sergienko I.V. Mathematical models and methods for solving discrete optimization problems. [Matematycheskie modeli i metody reshenia zadach diskretnoi optimizatsii] - K.: Naukova Dumka, 1985. - 384 p. 8. Vasiliev F.P. Numerical methods for solving extremal problems. [Chislennye metody reshenia ekstremalnykh zadach] - M.: Nauka, 1988. - 552 p.

9. Borovyk O.V., Borovyk L.V., Matokhniuk L.O. Higher Mathematics: elements of linear and vector algebras.
Analytical geometry. Part 1: Tutorial. [Vyshcha matematyka: elementy liniinoi i vektornoi alhebry. Analitychna heometriia. Chastyna 1: Navchalnyi posibnyk] Khmelnytskyi: NADPSU Publishing House, 2015 - 488 p. 10. Kurilin B.I. On the solution of the Chebyshev approximation problem for an incompatible system of nonlinear equations // Journal of Computational Mathematics and Mathematical Physics. [K resheniu chebyshevskoi zadachi priblizhenia dlia nesovmestnoi sistemy nelineinykh uravnenii // Zhurnal vychislitelnoi matematiki i matematicheskoi fiziki] - O.: 1970. T. 10. - № 1. S. 3-14. 11. Remiz E. Ya. Fundamentals of numerical methods of Chebyshev approximation. [Osnovy chislennykh metodov chebyshevskoho priblizhenia] - K.: Naukova Dumka, 1969. - 624 p. 12. Rambo J., Blaha M. UML 2.0 Object-Oriented Modeling and Development / J. Rambo, M. Blaha; - $2^{\text {nd }}$ ed. - St. Petersburg: Piter, 2007. - 544 p. 13. McDonald, Matthew. WPF 4: Windows Presentation Foundation in NET 4.0 with examples for C\# 2010 for professionals: - M.: LLC "I.D. William", 2011. - 1024 p.

14. Johnson Bruse Professional Visual Studio 2013/Bruse Johnson - Indianapolis: John Wiley \& Sons, Inc., 2014 $1048 \mathrm{p}$. 